\title{
Memória Postal Brasileira no Arquivo Público de Pernambuco
}

\author{
Brazilian Postal Memory in the Public Archive of Pernambuco
}

\begin{abstract}
Diego Salcedo
Doutor em Comunicação pela Universidade Federal de Pernambuco - UFPE. Professor Adjunto do Departamento de Ciência da Informação da Universidade Federal de Pernambuco - UFPE.

E-mail: salcedo.da@gmail.com
\end{abstract}

\section{Resumo}

Apresenta o projeto Legado da Memória Postal Brasileira: curadoria do Correio Geral do Arquivo Público de Pernambuco. Ação realizada em 2018, coordenada pelo Grupo de Pesquisa Imago e Humanidades Digitais da Universidade Federal de Pernambuco. Teve como parceiros o Arquivo Público Estadual Jordão Emerenciano, a empresa 3Ecologias Inovação e Pesquisa, e foi financiado a partir do edital público pelo Fundo de Incentivo à Cultura de Pernambuco. Seu objetivo foi higienizar, digitalizar e disponibilizar na Internet o volume primeiro da Série Correio Geral, de 1818. Participaram do projeto profissionais de áreas como História, Computação, Arquivologia, Jornalismo e Ciência da Informação, além de estudantes do curso de Biblioteconomia daquela Universidade. Foram realizados leituras e debates, capacitação técnica paleográfica, de descrição para documentos arquivísticos e sobre os softwares Atom e Archivematica. Aplicou diretrizes do Conselho Nacional de Arquivos e da Norma Brasileira de Descrição Arquivística. Concluiu que urge pensar, debater e criar políticas que tenham como objetivo fomentar o desenvolvimento de coleções, a organização de acervos memoriais, a formação e a conservação de longo prazo das redes e dos conteúdos digitais de instituições memoriais diversas e distintas, considerada a relevância de equipes pluridisciplinares.

Palavras-chave: Arquivo. Correios. Documento Postal. Memória.

\begin{abstract}
Presents the project Legacy of Brazilian Postal Memory: curation of the General Mail of the Public Archive of Pernambuco. Action taken in 2018, coordinated by the Imago Research Group and Digital Humanities of the Federal University of Pernambuco. It had as partners the State Public Archive Jordão Emerenciano, the company 3Ecologias Inovação e Pesquisa, and was financed from the public call by the Fund of Incentive to the Culture of Pernambuco. Its purpose was to Its goal was to sanitize, digitize and make available on the Internet the first volume of the 1818 General Mail Series. The project included professionals in areas such as History, Computing, Archives, Journalism and Information Science, as well as students of the Librarianship course from that University. Readings and debates were held on themes of common interest to the above areas, paleographic and descriptive technical training for archival documents, according to the policies envisaged by the National Archives Board and the Brazilian Standard for Archival Description, as well as periodic meetings to minimize doubts about the use of software Atom and Archivematica. It concluded that there is an urgent need to think, debate and create policies that aim first to foster the development of collections, the organization of collections of memorials, the formation and long-term preservation of networks and digital contents of diverse and distinct memory institutions, considering the relevance the formation of a multidisciplinary team.
\end{abstract}

Keywords: Archive. Mail. Memory. Postage Document.

InCID: R. Ci. Inf. e Doc., Ribeirão Preto, v. 10, n. 2, p. 158-174, set. 2019/fev. 2020 


\title{
1. Introdução
}

O século XXI vem se configurando pela rapidez do acesso, uso e circulação da informação devido ao aumento exponencial dos dispositivos tecnológicos e a massificação da conexão em rede. Neste cenário, a discussão em torno da preservação documental vem ganhando múltiplos desdobramentos, possibilitando assim, novas práticas de organização e disseminação de acervos de valor patrimonial.

Corroborando com essa perspectiva e trazendo novos apontamentos, Marques e Medeiros (2018, p. 9) afirmam que "a sociedade em rede requer da Arquivologia a (re)configuração de seu pensar-agir, no sentido de entender as complexidades dos tempos atuais." Nesse sentido, arquivistas de todo Brasil vêm repensando as suas atividades, de modo a possibilitar que os acervos estejam cada vez mais acessíveis aos usuários e que atendam a requisitos técnicos para garantir a sua preservação e uso.

Contudo, apesar do aumento do interesse no desenvolvimento dessas atividades, sabemos que o investimento público nas instituições de custódia desses patrimônios documentais no Brasil, ainda é muito escasso, nesse sentido, parcerias com universidades, setor privado e grupos de pesquisa pode ser uma solução para propiciar que ações de curadoria digital sejam desenvolvidas, de modo a garantir o acesso, uso e a preservação de informações arquivísticas.

Por outro lado, sob um olhar epistemológico da própria área de conhecimento nomeada Arquivologia, vale apontar para um debate teórico, em curso, que chama atenção para uma a necessidade de que as práticas em arquivos sejam mais do que, apenas, por exemplo: digitalizar e prover acesso público pela Internet, como indica Skarpelis (2019, p. 24):

\begin{abstract}
An epistemology of the archive has to consider the archive as a field in itself, a space for the production of historical knowledge, rather than seeing archival work simply as a form of fieldwork that extracts evidence or works on the basis of found objects. Framing the question of archival bodies around epistemological concerns allows addressing questions of positionality, subjectivity and a pluralism of meaning structures, thus productively melding the literatures of standpoint theory within sociology, memory studies within history, and postcolonialism within anthropology
\end{abstract}

Dito isso, o presente artigo relata sobre o projeto intitulado "Legado da Memória Postal: curadoria do Correio Geral do Arquivo Público de Pernambuco", realizado em 2018, coordenado pelo Grupo de Pesquisa Imago e Humanidades Digitais da Universidade Federal de Pernambuco (UFPE), em parceria com o Arquivo Público Estadual Jordão Emerenciano 
(APEJE), com a empresa 3Ecologias Inovação e Pesquisa, e financiado a partir do edital público pelo Fundo de Incentivo à Cultura (Funcultura/PE).

O objetivo do projeto foi higienizar, digitalizar e disponibilizar na Internet o volume primeiro da Série Correio Geral, de 1818, custodiado pela APEJE. Participaram das atividades de organização, tratamento e disseminação, desse patrimônio da memória local, regional, nacional e internacional, profissionais de áreas como História, Computação, Arquivologia, Jornalismo e Ciência da Informação, além de estudantes do curso de Biblioteconomia da UFPE.

O escopo temporal do projeto tratou o volume 1 , de um total de oito volumes que constituem o Fundo Governo de Pernambuco da APEJE. Os documentos são da administração pública do final do período colonial e dos primeiros 40 anos do Império, em que, no Rio de Janeiro, estava a Administração Geral dos Correios. Era por meio desse órgão que o Império se comunicava com o restante do território brasileiro para tratar de assuntos como envio de tropas e suprimentos, negociação de terras, ordens eclesiásticas e compra e venda de escravos.

Para cumprir as etapas previstas no projeto, foram realizadas leituras e debates sobre temas de interesse comum às áreas supracitadas, além de capacitação técnica paleográfica e descritiva para documentos arquivísticos, conforme políticas previstas pelo Conselho Nacional de Arquivos (CONARQ) e pela Norma Brasileira de Descrição Arquivística (NOBRADE), bem como encontros periódicos para minimizar dúvidas sobre utilização dos softwares Atom e Archivematica.

\section{Tessituras arquivísticas}

A Gestão de documentos é fundamental para nortear todo o ciclo de vida dos documentos, portanto, visa a racionalização e eficiência na produção, tramitação, uso, avaliação e arquivamento de documentos em fase corrente e intermediária, visando a sua eliminação ou recolhimento para a guarda permanente, conforme destaca o Arquivo Nacional (2005b). Contudo, para que os documentos estejam acessíveis aos usuários na fase permanente, duas atividades são essenciais: arranjo e descrição.

Desde um debate teórico internacional a colocação de Eastwood (2012, p. 4) sugere a exploração 
of fundamental concepts at the heart of archival theory, and therefore the complex process of arranging and describing archives, that he developed in several previous articles. He makes the case for more subtlety in our appreciation of the character of various archival aggregations, which he believes have never been easy to fix (that is, identify in one way) and are even less so in the digital age. In keeping with recent constructivist-oriented thinking to the effect that archives are formed and re-formed and never explicable from only one viewpoint, he challenges the traditional distinction between collections and fonds.

O arranjo consiste em uma derivação da classificação, seu objetivo é a ordenação de documentos oriundos da avaliação que possuem valor permanente, respeitando, sobretudo, o caráter orgânico do conjunto arquivístico. Conrado (2014, p. 29) destaca que "o arranjo é uma atividade matricial nos arquivos permanentes, pois a partir e baseado nessa organização que as demais atividades, tais como a descrição e a difusão passam a ser elaboradas".

A descrição, por sua vez, é a maneira como é estabelecida a relação entre os documentos custodiados pelas instituições e os potenciais interagentes. Ou seja, é a partir da descrição, e consequentemente dos instrumentos de pesquisa, que os usuários tomam conhecimento das informações contidas nos fundos documentais.

Vale esclarecer que o conceito de fundo arquivístico é entendido enquanto "um conjunto de documentos com mesma proveniência" (ARQUIVO NACIONAL, 2005a, p. 97), ou seja, esses documentos são produzidos ou recebidos nos processos que constituem as próprias funções e atividades das instituições públicas e privadas (VENANCIO; BARBOSA, 2018).

\begin{abstract}
A história das instituições se mistura com a história das pessoas que participam dela direta ou indiretamente. No caso de uma instituição pública muitas são as pessoas que participam desta interação (interagentes, se for considerado o momento atual), e essas memórias institucionais se misturam com a história da própria sociedade a qual está inserida. Enfim, as práticas de resgate da memória institucional fazem parte do resgate de uma memória que pertence a todos, talvez, no sentido universal do termo humanidade (SALCEDO; LIMA, 2018, p. 318).
\end{abstract}

Nos primórdios das práticas arquivísticas, a descrição tinha função de controle de acervo, contudo, com a Revolução Francesa e a abertura da função social e cultural dos documentos, a descrição passou a ser a ferramenta fundamental para a recuperação documental. A primeira obra que registra essa nova concepção e apresenta regras e normas para o trabalho de descrição é o Manual dos Arquivistas Holandeses (publicado em 1898 e é considerado por muitos estudiosos, o marco inicial da Arquivologia Moderna). Segundo Fonseca (2005, p. 39), “o manual acentua a necessidade de que a documentação seja descrita uniformemente, sem privilegiar este ou aquele documento". 
A partir do Manual dos Arquivistas Holandeses, a descrição arquivística passou a ter destaque nas discussões da área, ganhando cada vez mais notoriedade e novos desdobramentos. Contudo, diante deste cenário, algumas divergências começaram a surgir, bem como a falta de uniformização do processo de descrição, o que ocasionava em dificuldade dos usuários para compreender os instrumentos de pesquisa produzidos nas diferentes instituições de custódia. Nesse sentido, alguns eventos foram criados após meados do século XX para ampliar as discussões em torno da descrição e definir os fundamentos de sua prática.

Diante deste cenário e a necessidade de uniformização no processo de descrição nos arquivos em todo o mundo, foi publicada em 1994 a Norma Geral Internacional de Descrição Arquivística, conhecida como as ISAD (G).

A ISAD (G) padroniza a descrição arquivística em fundos como um todo e em suas partes e contém regras gerais que podem servir como base para a criação de normas locais. Vale destacar ainda que essa norma apresenta a descrição multinível, ou seja, do geral para o particular. Para Bellotto (2006), a estrutura multinível é o marco teórico da norma ISAD (G).

Assim, para realizar a descrição multinível, o profissional deve conhecer a organização do arquivo e compreender se a documentação descrita está a nível de fundo, série, dossiê/processo ou item documental, conforme destaca a norma:

Fundo - Conjunto de documentos, independente de sua forma ou suporte, organicamente produzido e/ou acumulado e utilizado por um indivíduo, família ou entidade coletiva no decurso das suas atividades e funções.

Série - Documentos organizados de acordo com um sistema de arquivamento ou mantidos como uma unidade, seja por resultarem de um mesmo processo de acumulação ou arquivamento, ou de uma mesma atividade, seja por terem uma forma particular ou devido a qualquer outro tipo de relação derivada de sua produção, recebimento ou uso.

Dossiê/Processo - Unidade organizada de documentos agrupados, quer para uso corrente por seu produtor, quer no decurso da organização arquivística, porque se referem a um mesmo assunto, atividade ou transação.

Item documental - A menor unidade arquivística intelectualmente indivisível (CONSELHO INTERNACIONAL DE ARQUIVOS, 2001, p. 15-16).

A criação da ISAD $(G)$ contribuiu para o intercâmbio entre as diferentes instituições pelo mundo, além de facilitar a promoção do acesso. Bellotto (2006, p. 183) afirma ainda que "só a descrição assim normalizada atingirá a desejada normalização universal e terá todas as condições para ser feita facilmente, de modo informatizado e uniforme".

A partir da publicação da Norma Internacional, vários países criaram a sua norma, contudo, tendo como referência os elementos usados nas ISAD (G). A Norma Brasileira é intitulada de NOBRADE e possui oito áreas (uma a mais do que a internacional) que 
compreendem um total de 28 elementos de descrição. Apesar desse número, apenas 7 elementos são obrigatórios: código de referência; título; data(s); nível de descrição; dimensão e suporte; nome(s) do(s) produtor(es); condições de acesso (somente para descrições em níveis 0 e 1).

Conforme fora dito anteriormente, o processo de descrição dá origem aos instrumentos de pesquisa, são eles que propiciam o acesso, a consulta e a divulgação do acervo. Cada instrumento tem características próprias, sendo mais ou menos detalhada em direção ao fundo documental. Bellotto (2006, p. 180) assevera que os instrumentos de pesquisa são "em essência, obras de referência que identificam, resumem e localizam, em diferentes graus e amplitudes, os fundos, as séries documentais e/ou as unidades documentais existentes em um arquivo permanente".

Assim, temos como principais instrumentos: guia, inventário, catálogo, índices, etc.

Fica claro que a digitalização é considerada, na lei, enquanto ação que pode agilizar o acesso e o uso da informação arquivística pelo usuário em geral. Porém, ela carece de uma estrutura política coerente com as atividades fins da instituição para o seu pleno funcionamento". Particularmente no que diz respeito ao processo da sua indexação e seu armazenamento. Posto que, de nada adianta um arquivo digital se não existirem métodos eficazes e eficientes de recuperação, salvaguarda (diante da constante obsolescência tecnológica) e de autenticidade e fidedignidade da informação (SALCEDO; OLIVEIRA; SANTOS, 2014, p. 88).

É nesse sentido que existe uma articulação entre áreas como Ciência da Informação, Arquivologia e Humanidades Digitais, a saber:

articula-se com a Ciência da Informação num universo amplo e complexo, tanto a partir dos debates teóricos, quanto sob uma perspectiva das práticas de organização, seleção, disseminação e curadoria digital. De fato, o debate epistemológico na Ciência da Informação não pode prescindir das práticas das Humanidades Digitais e os constantes desafios demandados pela contemporânea cultura digital e sua forte característica interdisciplinar (SALCEDO; BEZERRA, 2018, p. 74)

Contudo, com o advento tecnológico novas ferramentas e ambientes vem propiciando maior agilidade no processo de recuperação da informação, e consequentemente, para o acesso. Os instrumentos hoje, estão acessíveis em sistemas informatizados e através de ambientes confiáveis, conforme discutido na próxima seção. 


\title{
3. Softwares AtoM e Archivematica
}

Definida como um processo de técnicas operacionais “[...] referentes à produção, tramitação, uso, avaliação e arquivamento de documentos em fase corrente ou intermediária, visando a sua eliminação ou recolhimento" (ARQUIVO NACIONAL, 2005b, p. 100), a digitalização de documentos se apresenta como um procedimento complementar à gestão documental em face do novo arsenal tecnológico e dinâmico da necessidade de acesso e uso da informação pelos usuários.

A operacionalização dos documentos em formato digital requer a utilização de sistemas de gerenciamento que congregam artefatos específicos para seu manejo. No entanto, os sistemas devem ser operacionalizados para um serviço de informação que considere as especificidades de produção, tramitação, uso e arquivamento no escopo dos princípios e preceitos que orientam a gestão de documentos, conforme expõem Duranti e MacNeil (1996, p. 48-9, tradução nossa):

\begin{abstract}
um sistema de gerenciamento arquivístico de documentos compreende um conjunto de regras internamente consistentes que governam a elaboração, o recebimento, a retenção e o manuseio de documentos arquivístico corrente e intermediários, no curso usual e ordinário dos negócios do criador, e as ferramentas e mecanismos usados para implementá-las.
\end{abstract}

Nesse sentido, como indica Santos (2012 apud LIMA; FLORES, 2016, p. 212) "novos softwares surgem como ferramentas para colaborar na gestão, preservação e acesso às informações". Dessa forma, destaca-se a utilização de plataformas informatizadas para a difusão, descrição e acesso aos documentos de arquivo, tal como o ICA-AtoM.

Ao explicar a origem do AtoM, Pavezi (2013) cita que esse projeto, acrônimo para Access to Memory, resultou de um esforço colaborativo entre o International Council of Archives (ICA) e alguns parceiros e patrocinadores, como a UNESCO, a Escola de Arquivos de Amsterdam, o Banco Mundial, a Direção dos Arquivos de França, o Projeto Alouette Canadá e o Centro de Documentação dos Emirados Árabes Unidos.

A primeira versão do software foi lançada em 2006, chamado de ICA-AtoM v.0.1. No tempo de escrita deste artigo a versão utilizada no cenário internacional era a 2.4.1. O ICAAtoM é voltado ao ambiente WEB, com suporte multilinguístico e tem como objetivo auxiliar nas atividades da descrição arquivística em conformidade com os padrões do ICA. Ele foi desenvolvido para ser utilizado em conjunto com outras ferramentas de código aberto, a saber: Apache, MySQL, Hypertext Preprocessor (PHP), Symfony e Qubit Toolkit. 
Desde uma perspectiva de preservação digital de longo prazo e com utilização de software dois tipos de procedimento precisam de atenção, a saber: estrutural e operacional. O procedimento de ordem estrutural alude ao planejamento de adoção de normas, escolha de padrões e montagem da infraestrutura computacional. Por sua vez, o procedimento operacional é constituído pelo somatório da preservação física, lógica e intelectual dos documentos digitais (MÁRDERO ARELLANO, 2004).

Os procedimentos estruturais podem ser assinalados como sendo as políticas de preservação e os operacionais são as estratégias propriamente ditas. Uma estratégia de preservação digital pode ser entendida com um conjunto de objetivos e métodos para efetuar a manutenção em longo prazo dos documentos digitais, contemplando os seus respectivos objetos digitais e as suas informações relacionadas. Assim será possível a reprodução destes documentos arquivísticos digitais com caráter de autenticidade (WEBB, 2003).

É nesse contexto que a demanda tem aumentado na utilização do Archivematica: software livre para criação de repositórios digitais, desenvolvido em código aberto e com acesso ao código fonte, desenvolvido pela empresa Artefactual System. Conforme Fontana et al. (2014, p. 72),

informações encontradas no sítio do repositório este projeto conta com diversos colaboradores, dentre eles a UNESCO, o arquivo da cidade de Vancouver no Canadá, a Biblioteca da Universidade de British Columbia, o Arquivo do Rockefeller Center, e Arquivos Correntes e Permanentes da Universidade Simon Fraser (Simon Fraser University Archives and Records Management), além de outros colaboradores.

Consideradas as necessidades de manutenção e disponibilização de longo prazo do acervo digital resultante do projeto, a escolha em utilizar o repositório Archivematica deu-se por conta de suas funcionalidades computacionais, as quais contemplam algumas importantes estratégias de preservação de longo prazo, minimizando, assim, a obsolescência tecnológica e a incompatibilidade de formato, versões e suportes. Este conjunto de características cria as condições para que os documentos digitais subsistam autênticos, acessíveis e utilizáveis no futuro.

O Archivematica utiliza um padrão de micro-serviços que oferece um conjunto integrado de ferramentas de softwares que permite aos produtores no momento da inserção dos pacotes de informação migrar e converter os arquivos para formatos definidos pelo administrador, que podem ser estipulados previamente como padrões abertos e livres, visando a preservação e acesso a longo prazo, em conformidade com as recomendações do modelo conceitual OAIS (FONTANA et al., 2014, p. 74).

A imagem a seguir ilustra, didaticamente, como estão articuladas as funcionalidades da cadeia de custódia no Archivematica e os respectivos pacotes de informação que devem ser 
criados na instalação do repositório (SIP), no arquivamento do pacote (AIP) e na disseminação da informação (DIP):

Figura 1 - Modelo OAIS e cadeia de custódia SIGAD, Archivematica e ICA-Atom

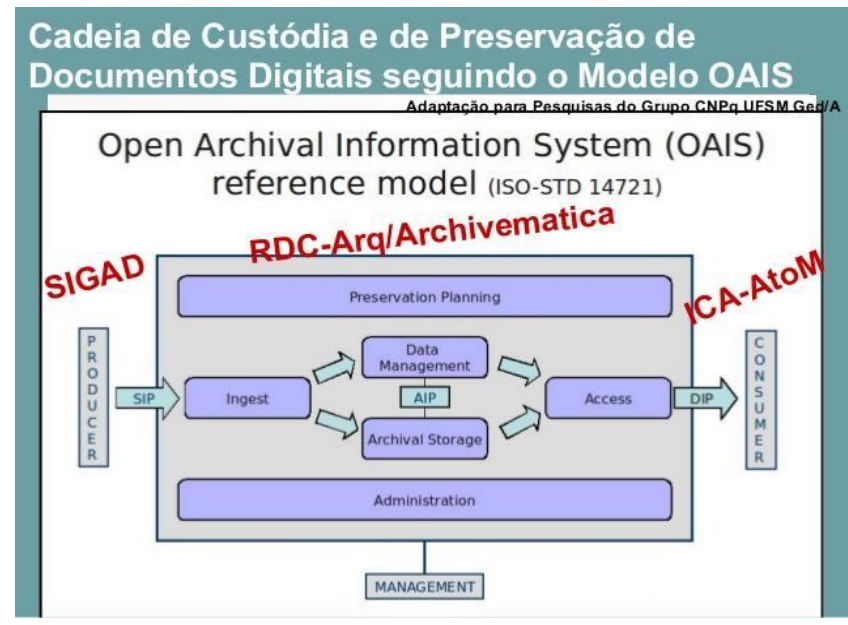

Fonte: Flores (2017)

\section{Relato de experiência}

O projeto do Legado da Memória Postal teve por objetivo geral a curadoria digital da subsérie Correio Geral: 1818-1840, do Arquivo Público do Estado de Pernambuco, para divulgar e prover ao público acesso irrestrito a desses documentos. Deste modo, para a realização desta finalidade, foram necessárias diversas ações preliminares, tais como o treinamento para manuseio de documentos fragilizados, processo decisório das especificações da digitalização, a identificação do conteúdo para a realização da descrição e a criação de uma plataforma digital.

O projeto aprovado usa a nomenclatura de "fundo", uma vez que esse era o termo usado pelo Arquivo Público no momento da escrita do projeto, contudo, ao longo da pesquisa, houve uma reorganização nos fundos e séries da instituição, respeitando o princípio da proveniência. Deste modo, o fundo Correio Geral tornou-se Série do Correio Geral, e o volume I, a subsérie

A Série Correio Geral é composta por Ofícios da Administração dos Correios ao Governador da Capitania, Presidente da Província e Governador do Estado sobre assuntos administrativos, condução das correspondências, mapas estatísticos e receitas e despesas. Portanto, os documentos apresentam informações relevantes sobre o dia a dia de Pernambuco. Essa Série está acondicionada em 7 encadernações, no qual abrange mais de cem anos de registros documentais. $\mathrm{O}$ formato de encadernações era comum até meados do século XX, em 
algumas instituições, para facilitar a custódia e o acesso, uma vez que estavam todos reunidos no mesmo lugar.

Além disso, os distintos processos de junção e guarda de documentos foram criados ao longo do tempo com o intuito de preservá-los, sendo a encadernação, um método usado para proteger os itens documentais avulso. Contudo, após anos de manuseio inadequado e falta de controle das condições ambientais, a série supracitada encontra-se com diversos problemas, tais como:

- ABRASÃO: desgaste da superfície decorrente da ação mecânica causadora de atrito. A abrasão fragiliza o material, ajudando no processo de rasgos e perdas de suporte (PAGLIONE, 2017).

- AÇÃO CORROSIVA: fragilidade e quebra das fibras de celulose do papel, causada pelo efeito corrosivo de elementos ácidos presentes em tintas, principalmente a ferrogálica, que apresenta grande concentração de ferro em sua composição (PAGLIONE, 2017).

- ATAQUE DE INSETOS: dano físico caracterizado por área com perda de suporte devido a ataques de insetos. Os insetos mais comuns que atacam materiais constituintes de livros (papel, couro, cola, tecidos) são: baratas, brocas, cupins e traças.

- DESCOLORAÇÃO DE ELEMENTO SUSTENTADO: Ocorre quando o pigmento do elemento sustentado (tinta, lápis, impressão etc.) sofre alguma decomposição físico-química causando esmaecimento ou alteração visual.

- FOLHA SEPARADA: Desmembramento de um caderno ou folha do resto do miolo, causado geralmente por fragilidade do papel ou da costura que o segurava ao conjunto da encadernação.

- MANCHA: Área do suporte de coloração ou tonalidade diferente, causada por substância que suja ou que desloca a sujeira interna do papel. Manchas podem causar danos ao papel ao inserirem substâncias de característica ácida ou catalisadoras de reações que deterioram a celulose.

- PASTA DESTACADA: Dano físico que ocorre quando uma das pastas da capa se desprende da lombada que permanece atrelada à encadernação. Geralmente é causada por um desgaste físico do suporte.

- RUGA: Caracterizado pelo franzido no papel, é um dano físico causado por forças mecânicas como manuseio, acondicionamento ou choque.

- SUJIDADE: Depósitos superficiais ou penetrantes de sujeiras (poeira, restos de comida, borracha, excrementos de insetos etc.). Sujidades atraem insetos, fungos e podem acidificar a região em que se depositam. 
Diante deste cenário e o curto tempo, optamos em iniciar as atividades deste projeto com o volume I, datado de 1818 a 1840, portanto, o mais antigo da Série Correio Geral. A escolha se deu pela importância histórica do conteúdo e pela emergência de salvaguardar o conteúdo informacional do volume, visto que as condições do material estavam em situação crítica.

Figura 2 - Condições de preservação (vol. I)
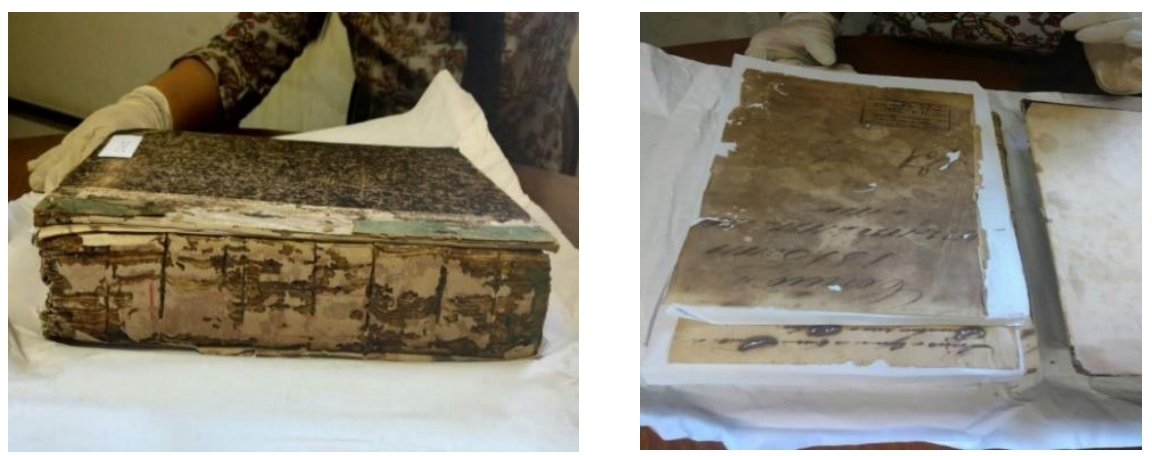

Fonte: Dados do projeto (2017)

Assim, o primeiro passo do projeto foi o treinamento para o manuseio adequado dessa documentação por parte dos bolsistas, visto que o manuseio incorreto pode acarretar em maiores danos na documentação, inclusive, com perda de suporte e a quebra total da encadernação. Deste modo, durante o processo de digitalização foi usado um scaner planetário com alta tecnologia, que captava a imagem sem a necessidade da desencadernação. Ademais, a passagem das folhas era sempre realizada com um suporte de papel alcalino, visto que algumas páginas estavam quebradiças devido ao alto índice de acidez. Outra recomendação foi o apoio a capa, para que a costura não sofresse ainda mais danos.

Figura 3 - Processo de captura da imagem
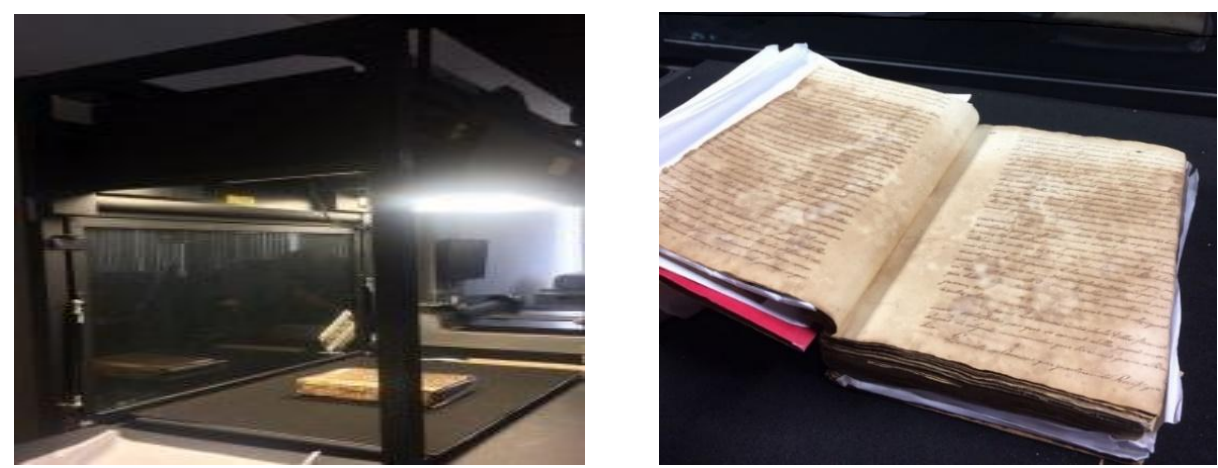

Fonte: Dados do projeto (2018)

Além das recomendações citadas acima, foi obrigatório o uso de equipamentos de proteção individual durante o manuseio da documentação. Segundo o Arquivo Nacional (2005) esta recomendação atende à manutenção da saúde de usuários e técnicos, considerando-se que 
no passado foi frequente o uso de inseticidas, que em muitos casos ainda preservam elevados níveis de toxidez.

Outrossim, pode existir esporos de microrganismos que também podem ser fatores de contaminação e toxidez ao usuário ou ao profissional. Tratando das especificações da digitalização, destacamos que seguimos o manual de Recomendações para digitalização de Documentos Arquivísticos Permanentes publicado pelo Arquivo Nacional em 2010, visto a necessidade de atender a todos os requisitos da curadoria digital.

Devido ao tamanho do volume e a sua fragilidade, utilizamos o scanner da marca Kirtas. Esse modelo utiliza uma câmera Canon EOS5d, que tem capacidade de resolução de até 21 megapixels. As imagens foram capturadas em 300 dpi, sendo a matriz digital no formato TIFF e sem nenhum tipo de tratamento que modificasse as características originais do documento.

Vale salientar que durante o processo de captura, a luminosidade foi controlada para que não houvesse nenhuma interferência na qualidade da imagem. Segundo o Arquivo Nacional (2015b) o ambiente deve ter controle na luminosidade, sejam os refletores utilizados para iluminar diretamente o documento seja as condições do local destinado a essa atividade (tipos e posicionamento), adequando-o aos requisitos técnicos necessários, como cor de paredes e piso, controle de aberturas (janelas e portas).

No final do processo de digitalização o volume foi acondicionado em uma caixa feita sob medida, com papel triplex de gramatura 375, com PH alcalino. Segundo Norma Cassares (2000, p. 35) "o acondicionamento tem por objetivo a proteção dos documentos que não se encontram em boas condições", deste modo, visando proteger o volume físico, foi realizado o acondicionamento para o retorno ao acervo do Arquivo Público de Pernambuco.

Finalizado o processo de digitalização e devolução do documento original, iniciamos as atividades de leitura paleográfica e descrição de documentos. O treinamento em Paleografia foi fundamental para compreender as informações registradas nos documentos, e, portanto, realizar a descrição com mais qualidade. Aline Krüger (2014, p. 213) assegura que o ensino da paleografia para os arquivistas é "[...] condição importante e imprescindível para o desempenho dessa profissão, pois além de auxiliar na leitura e interpretação de documentos, ela colabora na exata Classificação e Descrição dos mesmos”.

Iniciando a atividade de identificação, leitura e descrição foram contabilizados 314 documentos, contudo, foram processadas 453 imagens (há documentos com mais de uma 
página). A descrição seguiu utilizando como referência a Norma Brasileira de Descrição Arquivística (NOBRADE) e as necessidades do Arquivo Público de Pernambuco.

Conforme fora dito anteriormente, a Nobrade apresenta oito áreas centrais com o total de 28 elementos de descrição, contudo, apenas 7 elementos são obrigatórios, são eles: código de referência; título; data(s); nível de descrição; dimensão e suporte; nome(s) do(s) produtor(es); condições de acesso (somente para descrições em níveis 0 e 1).

Visando o maior número de informações, realizamos o preenchimento de todos os campos, contudo, só foram utilizados pelo Arquivo Público os campos obrigatórios para manter a padronização das demais séries que estão sendo descritas. Vejamos a imagem a seguir:

Figura 4 - Descrição no site do Arquivo Público de Pernambuco

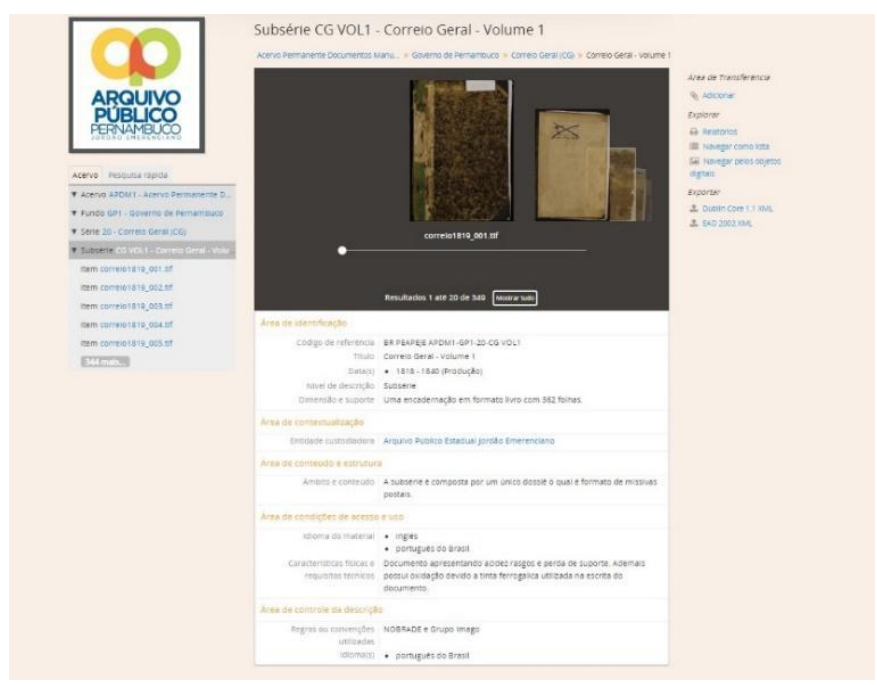

Fonte: https://bit.ly/2BVlA2l

O Arquivo Público vem utilizando o Archivematica e o ICA-AtoM para a preservação e acesso aos documentos, e ainda, visando seguir as recomendações e padrões do Conselho Internacional de Arquivos (ICA). Como fora dito, são ferramentas gratuitas que podem ser facilmente utilizadas no processo de descrição, ampliando o uso dos diversos usuários ao longo do tempo.

Corroborando desta perspectiva e trazendo novos apontamento, Flores e Hedund (2014, p. 28) afirmam: "ao constatar a compatibilidade do ICA-AtoM com a NOBRADE, o arquivista tem em suas mãos uma ferramenta de trabalho gratuita e pautada pelas recomendações arquivísticas, sem a necessidade de desenvolver ou adquirir um software no mercado". 
Finalizado os processos de digitalização, descrição e compartilhamento dos dados com o Arquivo Público, criamos uma plataforma digital para promover ainda mais a difusão e o acesso aos documentos objeto desse projeto. O conteúdo da plataforma atendeu a protocolos nacionais e internacionais de comunicação e interoperabilidade por meio do OAI-PMH, do Z39.50 e de linguagens computacionais XHTML, XML e PHP, a saber: http://imagohd.me/memoriapostal/

Na página há informações sobre o desenvolvimento do trabalho, detalhamento do valor cultural do acervo, equipe responsável pela execução do projeto, registros fotográficos e outros dados relevantes. Ademais, há um link direto para o site do Arquivo Público de Pernambuco visando o acesso a descrição e as cópias digitais. Essa metodologia foi usada para estreitar os laços de parceria entre o grupo de pesquisa IMAGO e a detentora da custodia do acervo. Além disso, direcionar o acesso às cópias dos documentos ao site do Arquivo Público, possibilita a divulgação de outros acervos relacionados e informações mais amplas, uma vez que a instituição está padronizando a sua descrição na estrutura multinível.

\section{Considerações finais}

Através do desenvolvimento do projeto Legado da Memória Postal foi possível perceber como é relevante respeitar cada etapa do tratamento arquivístico, para garantir o acesso à informação e a preservação do documento físico e digital. Em pleno século XXI, a digitalização surge como imperativo nas instituições custodiadoras de acervo, contudo, é preciso pensar nesse processo de forma mais abrangente e garantir a curadoria digital.

O projeto desenvolvido corrobora com as ações de preservação da memória digital recomendadas pela UNESCO na sua Declaração de Vancouver. Insere, ainda, o Brasil e, por sua vez, o Estado de Pernambuco, de maneira inédita, no cenário internacional neste tipo de ação cultural nos campos da Filatelia, da História Postal das práticas memoriais.

Ainda, a plataforma digital que foi desenvolvida nesse projeto, bem como a inserção da descrição e as cópias digitais no site do Arquivo Público de Pernambuco visou contribuir para a preservação, conservação e difusão da memória, da cultura e da identidade pernambucana em consonância com o Art. 3, Inciso VI do Plano Nacional de Cultura do Ministério da Cultura.

Isso demanda pensar, debater e criar políticas que tenham como objetivo primeiro fomentar o desenvolvimento de coleções, a organização de acervos memoriais, a formação e a 
conservação de longo prazo das redes e dos conteúdos digitais de arquivos, bibliotecas, museus, institutos de pesquisa e culturais, fundações públicas e privadas, bem como outros serviços de documentação existentes. É no tempo presente que a rede mundial de produtores e usuários da informação digital determinará o futuro cultural das inteligências coletivas.

O Brasil, situado nesse cenário de interconexão global em rede, é reconhecido e respeitado pela riqueza e diversidade de sua economia cultural. No entanto, carece de mais políticas que promovam amplo e irrestrito acesso da população aos equipamentos, espaços e acervos culturais, particularmente, de forma continuada e com qualidade.

Nesse sentido, a execução desse projeto foi apenas um passo diante de um longo caminho que ainda temos a trilhar, porém a divulgação desse trabalho pode fomentar para que novos grupos entrem nessa caminhada e ajudem a desenvolver políticas efetivas na promoção e acesso à informações relevantes que se encontram esquecidas em arquivos e bibliotecas de todo o mundo.

Por fim, vale destacar que a partir da execução desse projeto, foi possível uma troca de conhecimento por parte de todos os envolvidos. As atividades desempenhadas durante o processo, contribuíram com a formação profissional dos participantes, por isso, destacamos a relevância da formação de uma equipe interdisciplinar, na qual insere-se profissionais e estudantes de diferentes áreas, contudo, todas ligadas a finalidade das ações que seriam desenvolvidas.

\section{Referências}

ARQUIVO NACIONAL (Brasil). Dicionário de terminologia arquivística. Rio de Janeiro: Arquivo Nacional, 2005a.

ARQUIVO NACIONAL (Brasil). Recomendações para a produção e o armazenamento de documentos de arquivo. Rio de Janeiro: CONARQ, $2005 b$.

BELLOTTO, Heloísa Liberalli. Arquivos permanentes: tratamento documental. 4. ed. Rio de Janeiro: FGV, 2006.

CASSARES, Norma Cianflone. Como fazer conservação preventiva em arquivos e bibliotecas. São Paulo: Arquivo do Estado, 2000.

CONRADO, Flávia Helena. Arranjo, descrição e difusão do patrimônio documental arquivístico da Universidade Federal do Rio Grande do Sul. 2014. 184 p. Dissertação 
(Mestrado profissional em Patrimônio Cultural) - Universidade Federal de Santa Maria, Santa Maria - RS, 2014.

CONSELHO INTERNACIONAL DE ARQUIVOS. ISAD(G): Norma Geral Internacional de Descrição Arquivística. 2. ed. Rio de Janeiro: Arquivo Nacional, 2001.

DURANTI, Luciana; MACNEIL, Heithet. The protection of the integrity of eletronic records: an overview of the UBC-MAS research project. Archivaria. n. 42, p. 46-67, 1996. Disponível em: 〈https://bit.ly/2Y9hn4J >. Acesso em: 02 maio 2018.

EASTWOOD, Terry. Arrangement and description of archives. Archivaria, n. 74, p. 3-6, 2012. Disponível em: 〈https://bit.ly/2qUsV04>. Acesso em: 10 dez. 2019.

FONSECA, Maria Odila. Arquivologia e ciência da informação. Rio de Janeiro: FGV, 2005.

FONTANA, Fabiana F. et al. Archivematica como ferramenta para acesso e preservação digital à longo prazo Ágora, Florianópolis, v. 24, n. 48, p. 62-82, 2014.

FLORES, Daniel; HEDLUND, Dhion Carlos. A preservação do patrimônio documental através da produção de instrumentos de pesquisa arquivísticos e da implementação de repositórios arquivísticos digitais. Revista do IPHAN, Rio de Janeiro, n. 3, p. 1-31, fev., 2014.

FLORES, Daniel. Digitalização de documentos em fundos e coleções: acesso, metadados, autenticação e preservação. Palestra. Porto Alegre - RS. 38 slides, color, Padrão Slides Google Drive/Docs 4x3. 22 de março de 2017. Disponível em: 〈https://bit.ly/2QQWW9B $\rangle.$ Acesso em: 13 de jan. de 2019.

KRÜGER, Aline Carmes. O ensino de paleografia no curso de graduação em arquivologia da ufsc: um exercício com os documentos do Instituto Histórico e Geográfico de Santa Catarina. Revista Ágora, Florianópolis, v 24, n.48, p. 211-223, jan./jun., 2014.

LIMA, E. S.; FLORES, D. A utilização do ICA-AtoM como plataforma de acesso, difusão e descrição dos documentos arquivísticos de instituições públicas. Informação e Informação, Londrina, v. 21, n. 3, p.207-227, 2016.

Disponível em: <https://bit.ly/36IRlc3 >. Acesso em: $10 \mathrm{dez} .2019$

MÁRDERO ARELLANO, Miguel Ángel. Preservação de documentos digitais. Ciência da Informação, Brasília, v. 33, n. 2, p. 15-27, maio/ago. 2004. Disponível em: <https://bit.ly/2XxlbMi >. Acesso em: 12 jan. 2019.

MARQUES, Juliana Ferreira; MEDEIROS, José Washington de Morais. Do segredo ao acesso: entre a custódia documental e a gestão da informação à luz dos paradigmas arquivísticos. Perspectivas em Gestão \& Conhecimento, João Pessoa, v. 8, n. 3, p. 4-19, set./dez. 2018.

OGDEN, Sherelyn. Métodos de armazenagem e práticas de manuseio. Rio de Janeiro: Arquivo Nacional / The Commission on Preservation \& Access, 1997. (Caderno Técnico, Armazenagem e Manuseio, 1). 
RODRIGUES, Maria Solange P. Preservação e conservação de acervos bibliográficos. Pontifícia Universidade Católica do Paraná. In: ENCONTRO NACIONAL DOS USUÁRIOS DA REDE PERGAMUM, 9., 2007. Curitiba, 2007. Disponível em: 〈https://bit.ly/2Jtzq2f $>$. Acesso em: 20 jan. 2019.

PAGLIONE, Camila Zanon. Glossário visual de conservação: um guia de danos comuns em papéis e livros. São Paulo: Biblioteca Brasiliana Guita e José Mindlin, 2017.

PAVEZI, Neiva. ICA-AtoM: manual do usuário em língua portuguesa-BR. Santa Maria: Ed. da UFSM, 2013.

SALCEDO, Diego Andres; OLIVEIRA, Danielle A.; SANTOS, Thaís H. N. Acesso e dispositivos legais na gestão de informações arquivísticas. Ágora, Florianópolis, v. 24, n. 49, p. $79-100,2014$.

SALCEDO, Diego Andres; LIMA, Igor Pires. O papel do bibliotecário na prática de preservação da memória institucional: o caso do espaço memória da Justiça Federal em Pernambuco. Ágora, Florianópolis, v. 28, n. 57, p. 314-331, 2018. Disponível em: <https://bit.ly/2Puvyz4>. Acesso em: 10 dez. 2019.

SALCEDO, Diego Andres; BEZERRA, Vinícius Cabral Accioly. A gênese do repositório filatélico brasileiro: uma experiência interdisciplinar nas humanidades digitais. Informação e Sociedade: estudos, João Pessoas, v. 28, n. 3, p. 69-80, set./dez. 2018. Disponível em: <https://bit.ly/2t8smAj>. Acesso em: $10 \mathrm{dez} .2019$.

SKARPELIS, Anna. Life on file: archival epistemology as theory. Trajectories, v. 30, n. 2-3, p. 23-29, Winter/Spring 2019. Disponível em: 〈https://bit.ly/2skSAiJ〉. Acesso em: $10 \mathrm{dez}$. 2019.

VENANCIO, Renata Pinto; BARBOSA, Lidiany Silva. Como surgem os fundos arquivísticos: administração pública e produção documental em Minas Gerais. Acervo, Rio de Janeiro, v. 31, n. 3, p. 57-74, set./dez. 2018.

WEBB, Colin. Guidelines for the preservation of digital heritage. Preparado pela Biblioteca Nacional da Austrália para a Divisão de Sociedade de Informação, Unesco, relatório n. CI-2003/WS/3. 2003. Disponível em: <https://bit.ly/2oK7mem>. Acesso em: 12 jan. 2019. 